\title{
La entrada triunfal y la ciudad en los siglos XVI y XVII
}

\author{
Francisco javier Pizarro Gomez *
}

Uno de los acontecimientos festivos más importantes que podía vivir una ciudad de la Europa moderna es, sin duda alguna, la entrada triunfal. La llegada a la ciudad de monarcas, príncipes o altas personalidades con motivo de jornadas reales, casamiento, juramento, etc. se convertía en una ocasión para el regocijo común que alteraba el ritmo vital de la población. Desde el momento en que se anuncia la visita se iniciaba en la ciudad un complejo y costoso mecanismo que estaba sujeto a unas normas más o menos establecidas y que tenia entre sus fines principales la conversión de la llegada en una gran fiesta, cuya pompa u solemnidad no siempre eran acordes con la importancia del acontecimiento que se celebraba y casi nunca con las posibilidades económicas del municipio ${ }^{1}$.

En el caso de las jornadas reales, todas las ciudades, villas y aldeas por las que debian discurrir aquéllas viven de una $u$ otra forma ese suceso, no faltando un cierto impulso competititivo entre ellas. Procesiones, fuegos artificiales, arcos de triunfo e incluso reformas urbanísticas y arreglos de caminos serán algunas de las formas de expresión del homenaje al monarca, dependiendo de la disponibilidad financiera de la localidad y del plan previsto en la jornada la selección de aquéllas.

La complejidad y ambición de los preparativos con los que las ciudades desean homenajear a su ilustre visitante, sobre todo los de aquellas en las que se va a celebrar una entrada triunfal, llegarían incluso a alterar el programa y calendario previstos de la jornada. Es el caso del

" Departamento de Historia del Arte. Universidad de Extremadura.

' Deleito y Piñuela, J., El Rey se divierte. Madrid 1955, págs. 181 y ss. 
retraso que sufre la entrada de Margarita de Austria en Madrid en 1599, "la cual no podía ser antes del mes de junio por haberse començado á haçer estas cosas - se refiere el cronistas a los arcos de triunfo- tarde " ${ }^{2}$, o de la espera que debe realizar en Almada Felipe III desde el día 5 al 29 de junio antes de su entrada triunfal en Lisboa, aguardando, además de las galeras que debían llegar de España, a "que se acabasen los triunfos con que en ella avia de ser recebido" " ${ }^{3}$. Este último ejemplo de una de las más destacadas entradas triunfales del siglo XVIII nos da una idea de la importancia que este aspecto tenia en este tipo de acontecimientos.

Las ciudades que tienen el privilegio de gozar de la presencia y estancia del monarca o del príncipe se transforman para ofrecer un aspecto a la altura de las circunstancias. Esta metamorfosis oscila entre las operaciones de tipo urbanístico hasta las luminarias y fuegos artificiales, que en esa mutación urbana jugaban un importante papel ${ }^{4}$.

\section{LA ENTRADA COMO FIESTA URBANA}

Como ha indicado Chastel, el festejo regio es desde el Renacimiento un conjunto constituido por tres elementos fundamentales: la entrada triunfal, la falsa batalla y la comedia ${ }^{5}$. De estos tres elementos, es la entrada triunfal el espectáculo que cobraba un carácter más popular. La población, que no siempre tenía acceso a los otros dos aspectos del festejo real, no sólo lo tenía en la entrada triunfal, sino que formaba parte de la misma, participando como espectador y protagonista de su puesta en escena, ya que el marco en el que se desarrollaba aquélla era su ciudad y con ella y sus mandatarios homenajeaba a su monarca o príncipe. Se trataba pues de una fiesta pública en la que toda la problación participaba en algo que no era únicamente una ceremonia oficial ${ }^{6}$; desde

\footnotetext{
2 Cabrera de Cordoba, L., Relaciones de las cosas sucedidas en la Corte de España desde 1599 hasta 1614. Madrid 1857, pág. 17.

${ }^{3}$ Labaña, J. E., Viaje de la Catolica Magestad del Rey Don Felipe III N.S. al Reino de Portugal i relación del solemne recibimiento que en él se le hizo (Madrid 1622), pág. 8.

"Vid. Christout, M. F., "Les feux d'artifices en France (1606-1628)", en Les fêtes de la Renaissance, t. I. Paris 1975, págs. 247-257. pág. 419.

"ChASTEL, A., "Le lieu de la fête", en Les fêtes de la Renaissance, t. I. París 1975,

${ }_{6}$ Vid. Chartrou, J., Les Entrées Solennelles et Triomphales à la Renaissance (14841551). Paris 1928, pág. 8.
} 
lo enfáticos "triunfos" del Renacimiento a las pompas fastuosas del Barroco, la entrada triunfal unificaba socialmente a la población urbana en la preparación y contemplación de la ceremonia.

Es preciso entender, sin embargo, la fiesta urbana del Antiguo Régimen como un mecanismo e instrumento de poder en el que la espontaneidad popular quedaba encorsetada entre las estrictas disposiciones que regulaban el desarrollo de las entradas ${ }^{7}$. No faltaba tampoco en ese dirigismo una cierta teatralización del poder en cuya ficción se permitía intervenir a las clases inferiores, las cuales se veían temporalmente sumidas en un mundo fastuoso e ideal que nada tenía que ver con el de su realidad cotidiana $^{8}$.

Podemos definir la entrada triunfal como una fiesta colectiva en la que todos los estamentos de la sociedad urbana colaboran en función de sus medios y posición. Se trata de una manifestación común en la que la expresión culta se combinaba con la popular, aunque cada una tenia unos campos de actuación específicos. Cada ciudadano, con la decoración de sus ventanas y balcones, contribuía a embellecer el recorrido de la comitiva y a mudar el aspecto de la ciudad. Las fuerzas vivas de la ciudad jalonarán la "carrera" con los arcos y demás construcciones efimeras, cuya espectacularidad se verá realzada con el resto de la parafernalia preparada al efecto ${ }^{9}$.

Por otra parte, y a pesar de la influencia que entradas precedentes en otras localidades puedan ejercer, cada ciudad tratará de imprimir su

7 En Mérida y con motivo de la entrada triunfal que en dicha ciudad realiza Felipe III en 1619, se manda "pregonar que todas las ventanas de la plaça y calle de Santa Olalla estubiesen adereçadas con sedas, que los huespedes se recibiesen con mucho agasajo y buen ospedaje,..." (Relación del rescibimiento que la Ciudad de Mérica hizo a la Magestad del Rey Don Phelipe 3, Nro. Señor, Sábado, 4 de mayo de 1619 (Mérida 1619), f. 1.

${ }^{8}$ Sobre este aspecto véase BONET CORREA, A., "La fiesta barroca como práctica del poder ", Diván, 1979, págs. 53 y ss.

${ }^{9}$ En el caso de la entrada de Felipe II en Sevilla en 1570, "el ornato de las calles era riquísimo, y bien dispuesto, porque ya todos tienen en sus casas salas adereçadas de muchas maneras de costosas redes, sedas, y de cueros, que con la pintura suplen el no ser de telas de oro, donde la obra sobrepuja a la materia " (MAL LARA, J. de, Recibimiento que hizo la Muy Noble y Muy Leal Ciudad de Sevilla a la C.R.M. del Rey don Phelipe N. $S$., Sevilla 1570 , pág. 165 v. En Burgos un año después y con motivo de la visita de la futura esposa de Felipe II "se encendieron en toda la ciudad grandissima cantidad de hachas, lumbreras y faroles en las ventanas y grandes hogueras y fuegos en todas las calles y Plazas, que daban tan resplandeciente luz, que verdaderamente parecia que toda la ciudad ardia a los que de fuera miraban" (Relación verdadera del recibimiento que la Muy Noble y Muy Leal Ciudad de Burgos, Cabeça de Castilla, y Cámara de su Magestad, hizo a la Magestad Real de la Reyna nuestra Señora doña Anna de Austria... Burgos 1571, en Relaciones de los reinados de Carlos V y Felipe II de la Sociedad de Bibliófilos Españoles. Madrid 1951, pág. 261). 
propia personalidad a la ceremonia, lo que se plasmaba tanto en la selección de una temática local para decorar los arcos triunfales como en la exaltación de las bondades de la ciudad y su lealtad al monarca o príncipe. Es caso ilustrativo el de Burgos en 1571 y la entrada triunfal que prepara la ciudad para recibir a la futura esposa del monarca español ${ }^{10}$. En efecto, en dicha entrada triunfal, "huyendo -como expresaba el cronista- de las fábulas y alegorías que en otros recibimientos se han usado" ", la mayor parte de los elementos de su repertorio iconográfico y narrativo se refería, como en el caso del arco que se dispuso en la Puerta de San Martín, "a la antigua fundación de la ciudad de Burgos y leal proceso de ello, con la memoria de los fundadores y moradores que siempre en ella florescieron...." ${ }^{12}$.

Por otra parte, era frecuente dotar a la entrada triunfal y su ornamento de una simbología urbana que iba desde la entrega de la ciudad al visitante hasta la reivindicación política. La ciudad hace pública expresión de su entrega con la ofrenda de llaves o del corazón que normalmente realizan representaciones angélicas o alegóricas de la ciudad desde un arco de triunfo o una puerta de la ciudad. Entre los muchos casos que podríamos citar, hemos elegido el que describe el cronista de la entrada de Felipe IV en Barcelona en 1626 por ser un ejemplo perfectamente ilustrativo de la escenografia y significación de lo que en las entradas triunfales de los siglos XVI y XVII se convertiria en un elemento tradicional de la fiesta pública junto con los arcos triunfales, los fuegos de artificio, las batallas simuladas y las representaciones tetrales ${ }^{13}$. Expresaba el autor de la crónica de la entrada citada lo siguiente:

"Llegando a la puerta que estava emparejada dende una nube que estavae entre las dos torres, baxó un Angel que después de aver dado a su Magestad la bien venida, y otros muchos cumplimientos de parte de la ciudad, le ofreció las llaves della, para que como a dueño y señor entrasse en ella..." ${ }^{14}$.

${ }^{10}$ Sobre la entrada de Ana de Austria en Burgos véase Sanz, M. J., "Festivas demostraciones de Nimega y Burgos en honor de la Reina Doña Ana de Austria", B.S.A.A., XLIX. Valladolid 1983; págs. 375-395.

"Relación verdadera del recibimiento que la Muy Noble y Muy Leal Ciudad de Burgos..., págs. 178 y ss.

${ }^{12}$ Ibidem, pág. 179.

13 Sobre la escenografia teatral del acto oferente véase el articulo de SHERgolo, N.D., "Fête et théátre en Espagne au XVI siècle", en Les Fêtes de la Renaissance, vol. III. Paris 1975, págs. 451-459.

${ }_{14}$ Felicissima entrada del Rey Nuestro Señor en la Ciudad de Barcelona, y sumptuoso recibimiento, y fiestas que la dicha ciudad ha hecho a su Real Persona (Barcelona 1626), f. 2. 
Pero, como antes hemos señalado, la ciudad puede llegar a recabar de su ilustre visitante su atención y convertir la entrada triunfal en un motivo para la súplica reivindicativa. Así, afirmaba el relator en 1571 que "usa la ciudad de Burgos su antigua costumbre de suplicar a todos los Reyes en sus primeros recibimientos que entren por la puerta de San Martin" ${ }^{15}$. Ejemplo singular del alcance que a veces tenia la reivindicación fue el de Lisboa en 1619, cuando desde alguno de los arcos triunfales preparados para recibir a Felipe III se expresaba el deseo de algunos estamentos de la ciudad por hacer de Lisboa la capital del imperio español ${ }^{16}$.

Este último ejemplo es también ilustrativo del gran peso específico que tienen los promotores de la entrada triunfal y entre los cuales se encuentran el concejo, las cofradías y las entidades comerciales y artesanales, además de otras instituciones. Cada entidad profesional o grupo nacional que sufraga la construcción de una obra efímera para la entrada triunfal realiza con ello un acto de afirmación de su propia existencia, poder y virtudes. Por otra parte, sin el concierto de estas entidades los municipios no siempre hubieran podido soportar los grandes gastos que suponían las fiestas de esta naturaleza, sobre todo en época barroca. Las ambiciosas pompas con que las ciudades reciben a los monarcas y príncipes en los siglos XVI y XVII superaban normalmente las posibilidades económicas de los fondos concejiles; no es de extrañar por tanto que en aquellas ciudades en las que no existen esos grupos profesionales, el ayuntamiento tenga que recurrir a todo tipo de operaciones financieras para reunir los fondos necesarios ${ }^{17}$.

\section{LA TRANSFORMACIÓN DE LA CIUDAD}

Señalábamos antes que la entrada triunfal, además de alterar el tiempo vital de la ciudad, transforma el espacio cotidiano de ésta por otro tan espectacular como ficticio que, en muchos casos, llega a la formula-

\footnotetext{
${ }^{15}$ Relación verdadera del recibimiento que la Muy Noble y Muy leal Ciudad de Burgos..., pág. 178.

16 "Dando a entender, que con tales compañeros se governará bien la Monarquia de España, de la qual haziendo cabeça a Lisboa, que sola es capaz y merecedora de su trono, carecerá de límites su imperio" (LABANA, J.B., op. cit., pág. 33v.)

${ }^{17}$ Es el caso de Mérida en 1619 cuando se inician los preparativos para recibir a Felipe III; para ello se solicita de la Corte la toma de 16.000 ducados a censo, de los cuales se concederían únicamente la mitad, lo que obligó a la ciudad a pedir dinero prestado "de diferentes partes" (Relación del rescivimiento que la ciudad de Mérida..., f. 80).
} 
ción humanista de la ciudad ideal con una evolución de formas estilísticas según la época artística en la que se desarrolla y con una subyacente finalidad simbólica y política ${ }^{18}$.

Lógicamente, uno de los aspectos más llamativos de la mutación urbana es el de las construcciones efímeras que jalonan los recorridos de las comitivas durante la entrada y la estancia real o principesca. La frecuente grandiosidad de sus dimensiones y el primor de sus detalles decorativos sorprendían tanto a la población que veía levantarlos como a los huéspedes homenajeados. Pero el arco triunfal, además de unas caracteristicas arquitectónicas y decorativas más o menos definidas, tenía también por su propia naturaleza unas peculiaridades urbanísticas, que la tratadistica se habia encargado de definir ${ }^{19}$.

El arco triunfal mantenía, lógicamente, con la ciudad una relación que determinaba su ubicación y estructura. En efecto, el emplazamiento del arco o de los arcos preparados para una entrada triunfal dependia de factores esencialmente urbanos, como la estructura de la ciudad, la disposición de sus entradas más importantes, etc.

El recibimiento y, normalmente, el primer arco triunfal se disponía en la puerta o entrada principal de la ciudad, cuya decoración con pinturas, colgaduras y otros adornos suplía a veces la construcción de aquél. A continuación plazas y calles mayores son, por regla general, los lugares en los que no falta el emplazamiento de algún arco de triunfo. El resto de aquellos arcos que debían adornar el recorrido de la comitiva hasta la llegada a su lugar de residencia (palacio, alcázar, etc.) se disponía en las calles y plazas más importantes o habitados por los gremios profesionales que participaban en la fábrica de aquéllos ${ }^{20}$.

18 Vid. Sebastian Lopez, S., Arte y Humanismo. Madrid 1978, pág. 232.

19 Asi, por ejemplo, Alberti al referirse a la razón y origen de los arcos triunfales afirmaba lo siguiente: “Muy acommodadamente fabricaremos el arco en aquel lugar donde se terminare la calle que va a la plaça o mercado, y principalmente en la calle mayor (interpretación del traductor español de lo que Alberti llama via regia), porque ansí llamo yo la calle que dentro de la ciudad es más principal” (ALBERTI, L.B., Los diez libros de arquitectura. Madrid 1582, libro octavo, capitulo VI, pág. 250).

${ }^{20}$ Sirva como ejemplo el recorrido que realiza Felipe IV por Sevilla en 1624: “Passo su Magestad por los Quatro cantillos, y llegó a San Basilio; passó a la Alameda, y por junto al hospital del Amor de Dios. Entró en la plaça del barrio del Duque, y por la calle de Sierpe; entró en la plaça de San Francisco; passó ala calle de Génova, entró en Gradas, y llegó a la Iglesia Mayor, que le hizo alegre salva con música de campanas. Passó por el arquillo de San Miguel, llegó a la lonja, trato, y comercio de mercaderes, y por la puerta de la montería se entró en sus Reales Alcáçares" (Entrada del Catolicissimo Monarca de España Felipe III en la muy noble y leal ciudad de Sevilla, viernes primero de Marzo de 1624" (Sevilla 1624), f. 3. 
Es necesario contemplar el arco de triunfo en función del lugar en el que se levanta, pues la estructura de aquél dependía en gran medida de ese factor, como ha indicado Bieniecki ${ }^{21}$. El lugar condicionaba no sólo anchura y profundidad del arco, sino también su estructura. Así, mientras los arcos ubicados en las calles disponian de dos fachadas, los dispuestos en plazas y otros espacios abiertos se podian estructurar en cuatro frentes, como es el caso del arco que se levanta en la Puerta del Sol para recibir a Mariana de Austria y cuyas fachadas «miraban á seis calles; la anterior, à la de Alcalá, i Carrera de San Geronimo; la posterior, à la Calle Mayor; el un costado, á la de las Carreras; i el otro, á la San Luis, i Carmen" ${ }^{22}$.

Pero no todas las operaciones que se llevan a cabo en la ciudad con motivo de acontecimientos de esta naturaleza tenían una vida perecedera como el arco de triunfo hasta aqui reseñado. La entrada triunfal implicaba con frecuencia la necesidad de realizar operaciones urbanisticas para que aquélla se desarrollara con mayor esplendor, lo que después redundaba en la mejora de la estructura urbana de la población. Una de estas operaciones a la que nos estamos refiriendo es el derribo de edificaciones con el fin de ensanchar el espacio urbano en el que debía ubicarse una construcción efímera. Así ocurre, por ejemplo, en Sevilla en $15700^{23}$ o en Lisboa en $1619^{24}$. Pero no siempre era necesaria la construcción de obras efimeras para justificar estos derribos, pues en la mayoria de los casos eran el resultado de una mentalidad urbana moderna, entre cuyos principales objetivos se encontraba el deseo de ensanchar y "hermosear" las calles.

Este último es el caso de Segovia en 1570, entre cuyos preparativos para recibir a Ana de Austria el gobernador mandó demoler tres casas en una de las calles, pues con ello mejoraba la perspectiva de la misma

${ }^{21}$ Vid. BIENIECKI, Z., "Quelques remarques sur la composition architecturale des arcs de triomphe a la Renaissance", Les Fêtes de la Renaissance, t. III. Paris 1975; págs. 201217.

22 RamiRez de Prado, L., Noticia del recibimiento i entrada de la Reyna Nuestra Señora doña Maria Ana de Austria en la muy noble y leal coronada villa de Madrid (Madrid 1650). pág. 54 .

${ }^{23}$ En las proximidades de la que a partir de entonces se llamaria "Puerta Real» y a raiz de las construcciones efimeras que alli se levantan: "No fue pequeño trabajo hazer quadrado este espacio en tan breve tiempo quitando una casa que estava alli, y muralla fortissima, que se rompió y limpió todo brevemente, levantando las paredes de ambas partes, y encalándolas" (MAL LARA, J. de, Recibimiento que hizo..., pág. 160).

${ }^{24}$ Con motivo de la entrada de Felipe III, los ingleses residentes en Lisboa levantan un arco triunfal en el sitio "en que de antes avia en el muro dos arcos antiguos de canteria, los quales la ciudad mandó derribar, i muchas casas sobre ellos edificadas" (LABANA, OP. cit., pág. 23 v.). 
desde el Alcázar ${ }^{25}$, o el de Burgos en 1571, en cuya plaza se habian derribado algunas casas y la fuente "para que estuviese más claro y desembarazado el camino que por ella habia de hacer su Magestad,..." ${ }^{26}$. Es también el caso de Madrid en 1598 y a raíz de la entrada de Felipe II, con motivo de lo cual se derriban numerosas casas y se ensanchan diferentes calles ${ }^{27}$, o el de la misma ciudad un año después, cuando para la entrada de la reina se derriba "una acera de casas de la Platería para ensanchar la callle... y las que había desde la Plaza de San Salvador hasta Santa María se han derribado hacia la parte de la cárcel de la villa para ensanchar la calle" ${ }^{28}$.

Es necesario contemplar éstos y otros muchos ejemplos dentro de un fenómeno común a las ciudades españolas del siglo XVI, como es el de la mejora de su estructura vial y el desarrollo urbano que se operan como consecuencia de un fenómeno expansivo de tipo demográfico y arquitectónico, así como de una mentalidad urbana moderna dirigida a adaptar la ciudad a sus nuevas necesidades.

Dentro de este deseo de mejorar el aspecto de las ciudades aprovechando la visita real, hay que contemplar también las construcciones no efímeras que se levantan para conmemorar aquel acontecimiento. Como ocurre con el arco que en el lugar llamado de las Casas de Fernán González se levanta en el Burgos de 1587 con motivo de la visita de Felipe $1{ }^{29}$ o de la "portada de piedra" que en 1599 se levanta en Madrid entre otros preparativos para recibir a la reina ${ }^{30}$. Sin embargo, el deseo de construcción de arcos permanentes y dar a estos su verdadero y antiguo sentido de tipo conmemorativo tropezaba normalmente con diferentes dificultades, como la falta de tiempo o de fondos para poder ejecutarlos ${ }^{31}$. Si podrán en cambio las poblaciones proceder casi siempre

${ }^{25}$ Fernandez de HerRera, J., Relación verdadera del recibimiento que hizo la ciudad de Segovia a... doña Ana de Austria... (Alcalá 1572).

${ }^{26}$ Relación verdadera del recibimiento que la Muy Noble y Muy Leal Ciudad de Burgos..., pág. 254

27 Relación y forma del recebimiento que la villa y Ayuntamiento de Madrid hizo al Rey Don Felipe Nuestro Señor, Tercero deste nombre, á la entrada que su Magestad hizo en ella el Domingo ocho de Noviembre, de Noventa y ocho, aviendo caminado este dicho dia desde el Pardo... (Sevilla 1598), $\mathrm{f}$.

28 Cabrera de Cordoba, L., Relaciones de las cosas sucedidas en la Corte de..., pág. 13.

29 Vid. SANZ, M. J., op cit., pág. 383.

30 «Hase puesto la mano en hazer los arcos para la entrada de la Reina, y hacer una portada de piedra á los caños de Alcalá cerca del Pardo,..." (CABrera DE CORDOBA, L., Fielaciones de las cosas sucedidas en la Corte..., pág. 17).

${ }^{31}$ “Procuró hacer la ciudad un arco triunfal de piedra y ladrillo encalados y cortados para que quedase en memoria de la entrada de su magestad y por parecer a los maestros 
a una politica de mejora de caminos y puentes. En Burgos y en 1571 "se tuvo gran cuenta con aderezar todos los caminos que cerca de la ciudad habia y de hacer muy buenas puentes sobre el rio para que sin rodeo pudiese su Magestad pasar a las Huelgas donde habia de dormir» ${ }^{32}$. No faltaba tampoco una adecuada política urbana para que el aspecto de la ciudad estuviera durante el tiempo que dura la estancia del rey o del príncipe dentro de las mejores condiciones higiénicas y de habitabilidad. Así, durante el tiempo que Felipe IV permanece en Sevilla en 1624 «las calles estuvieron... más limpias que han estado muchos años ha, mediante la diligencia del Señor Asistente, y la falta de los coches, que por más de treinta días estuvieron impedidos" ${ }^{33}$.

\section{ENTRADA TRIUNFAL Y CIUDAD IDEAL}

Como hemos señalado con anterioridad, toda esta política de transformación de la ciudad mediante arcos de triunfo, derribos, ensanches, nuevas construcciones, arreglo de calles y caminos, etc. iba dirigida a transformar la ciudad real en una ciudad ideal, que es precisamente lo que diferencia las entradas triunfales del siglo Xvi de las de la centuria anterior ${ }^{34}$. Pero si todo ello no era suficiente, los promotores de la entrada contaban aún con otros recursos como eran las llamadas «perspectivas", arquitecturas pintadas que normalmente recreaban en trompe l'oeil espacios urbanos ideales, como es el que se idea en Burgos en 1571 y que describe asi el cronista:

"De este arco (el que se situó a la salida de la calle de la Puebla) hasta la puerta de Palacio estaba un perfecto edificio, el cual represen-

\footnotetext{
que no avia tiempo para que la obra se hiciese segura por no se poder enjugar ni sufrir el peso del dicho arco estando fresca, se hizo un arco a la entrada de la calle de la Encarnación de gentil vista y arquitectura" (Archivo Municipal de Trujillo. Legajo 84. Libro de Acuerdos de 1610-1619, "Relación de la entrada del Rey", f. 490).

${ }_{32}$ Relación verdadera del recibimiento que la Muy Noble y Muy Leal Ciudad de Burgos..., pág. 173.

${ }^{33}$ Entrada del Catolicissimo Monarca de España Fetipe III en la muy noble y leal ciudad de Sevilla..., f. 3.

${ }^{34}$ Sobre este aspecto y su sentido político absolutista puede verse el trabajo de CHECA, F., y DIEZ DEL CORRAL, R., "Arquitectura, iconologia y simbolismo: La entrada de Margarita de Austria, mujer de Felipe III de España en Milán el año 1598m. Volumen $V$ de las Actas del XXIV Congreso Internacional de Historia del Arte del CIHA. Bolonia 1981, págs. 73-83.
} 
taba la pintura de una muy perfecta ciudad, puesta en muy buena perspectiva, en las calles, casa y plaza y ventanas, tan bien repartidas que aunque era el sitio breve se remediaba este inconveniente con la subtileza, traza y buen ingenio, del arquitecto y pintor. A la una parte se veían sus compartimentos y en ellos las tiendas con sus torres y capiteles, y en lo más alto su reloj que daba a todo el edificio muy gran lustre y claridad de lo que era" ${ }^{35}$.

En el siglo XVII, cuando se incrementa el empleo del lenguaje clasicista del arco de triunfo, como elemento portador de un mensaje ideal y político, el uso de ese idealismo urbano ficticio adquiere su total madurez, siendo expresión de ello las fantásticas "perspectivas" que recreaban el marco de ficción adecuado a un espacio de tiempo igualmente ficticio, como era e! de la fiesta urbana para la población y cuya mayor espectacularidad con respecto a épocas anteriores correría pareja a la evolución que experimenta la escenografia teatral ${ }^{36}$. En el siglo XVII las "perspectivas" se enriquecen con los juegos espaciales del urbanismo barroco y con los avances que en el arte de la escenografía teatral desarrollan los tramoyistas italianos de la Corte, cuya participación en las fiestas reales de esta naturaleza no es extraña ${ }^{37}$, así como en los trompe l'oeil que los pintores boloñeses Mitelli y Colonna desarrollan en sus espacios y arquitecturas fingidas desde su llegada a Madrid a mediados de siglo. La búsqueda de diferentes ángulos visuales y puntos de vista, la valoración de los volúmenes, así como el deseo de asombrar al espectador son notas que definen tanto las "perspectivas" teatrales como las urbanas ${ }^{38}$.

${ }^{5}$ Relación verdadera del recibimiento que la Muy Noble y Muy Leal Ciudad de Burgos..., pág. 235.

36 Vid. Ruiz Lagos, M., "Técnica escenográfica en el teatro simbólico barroco", Goya, 169-171. Madrid 1982, págs. 82-91.

${ }^{37}$ Es el caso de la participación del famoso pintor, ingeniero y jardinero florentino Cosme Lotti en las fiestas reales del Retiro en 1637 (Vid PIzARRO Gomez, F. J., «Arte y espectáculo en las fiestas reales del Retiro en 1637", en Norba-Arte, VII, 1987, págs. 133139.

38 Siguiendo con el ejemplo de Cosme Lotti, Ceán Bermúdez cita la escenografía que el italiano crea para la obra de Lope de Vega Selva sin Amor, para la cual "trazó y pintó Lotti el teatro en el que aparecieron excelentes perspectivas de mar y de selva con puntuales vistas del bosque de la casa del campo y puente de Segovia... Estas máquinas, pintura y todo el aparato, merecieron la admiración de los espectadores..." (CEAN BERmúdEz, J. A., Diccionario histórico de los más ilustres profesores de las Bellas Artes en España. Madrid 1800, vol III-IV, pág. 52). Otro escenógrafo italiano, Bachio dil Bianco, preparaba en el Buen Retiro y en 1652 la escenografia para el estreno de la comedia de Calderón de la Barca La fiera, el rayo y la piedra, lo que constituyó, a decir de León Pinelo, "de las mayores y más vistosas invenciones, adornos y "perspectivas" que se han puesto en el teatro" (LEON Pinelo, A. de. Annales o Historia de Madrid desde el Nacimiento de Cristo Nuestro Señor, hasta el año 1658. Madrid, Edición del Instituto de Estudios Madrileños, 1970, pág. 348. 
Valga como ejemplo de lo que decimos la "perspectiva" que se recrea en el Madrid de 1650 con motivo de la entrada de Mariana de Austria y que describía así el autor de la crónica:

"Desde monte hasta el primer Arco, dexando a mano derecha la Carrera de Alamos, que por aquella parte le servia de bastante ornato, se corrió á la izquierda (atajando las Ruinas d'el camino de Atocha) una hermosa perspectiva, de Galerias, Palacios i Jardines, cuyo largo era de docientos $\mathrm{i}$ ochenta pies; i de alto veinte i cinco; contenida de un solo cuerpo que remataba en un Pedestal balaustrado de seis pies de alto. Dividióse en quatro Fachadas de la misma traça, de veinte i seis pies de ancho cada una, resaltadas á fuera en seisabo, fingiendo aver habitación cerrada a ellas.

La causa d'estas divisiones, fue la dificultad que halló el Artifice, al executarla, en tan grande superficie por la corta distancia, á que se miraba, que no pudiendo gobernarla de un solo punto, puso siete, á otras tantas Estaciones; $i$ con tal destreza las unió, que no implicaron á lo que la naturaleza enseña; ni á el Arte, que la imita; quedando la vista dos veces engañada, en la Representación de los objetos, i en el Artificio, que tan distintos aspectos seducía en uno: primor, que sería posible no averse visto executado, en otra Perspectiva, por ser tanta su longitud, i altura.

De las cuatro fachadas estaban dos á los extremos, por remate; i las otras dos en el Intermedio, dejando tres espacios. En el enmedio de noventa i dos pies, i los colaterales, de quarenta.

En estos se fingieron, en el vano interior Ambitos ó Zonjas, adornadas de colunas jonicas, que plantadas, sin pedestal en el pavimento, con una cornisa arquitrabada, recibían arcos, i vueltas, en crucería. Tenia cinco Puertas; tres en el intermedio, i una en cada lado, sin otras ocho, que cerraba un antepecho, de balaustres; i por ellas, i las ventanas correspondientes, se descubrían, á lo lejos deleitosos Paises, de Jardines i Casas de Placer, con sus quadros y fuentes..." ${ }^{39}$.

Como puede apreciarse, algunos de los recursos de la "perspectiva" evocan escenarios teatrales, pues no en balde ambos procuran recrear un ámbito ficticio e ideal para el desarrollo de una representación, que en el caso de las entradas triunfales adquiere connotaciones simbólicas y políticas muy definidas.

Pero hay casos en los que la ficción se lleva aún más lejos y el marco urbano se convierte en un auténtico escenario teatral donde se desarrolla una entrada triunfal igualmente ficticia. De ello es ejemplo sin-

${ }^{39}$ Ramirez de Prado, L., Noticia del recibimiento i entrada de la Reyna Nuestra Señora... (Madrid 1650), pág. 54. 
gular el de las fiestas reales que se celebran en el Buen Retiro con motivo de la llegada de la princesa de Cariñano y de la proclamación de Fernando III, rey de Hungria y cuñado del monarca español, como Rey de Romanos ${ }^{40}$. Las fiestas tienen lugar en 1637 y en el transcurso de las mismas Felipe IV realiza una entrada triunfal fingida en un escenario urbano efímero ${ }^{41}$. En efecto, para el desarrollo de los acontecimientos se construye una gran plaza de madera de 600 pies de largo y 530 de ancho, cuyos cuatro frentes estaban poblados de ventanas, las cuales se cifraron en 488 y se dispusieron en dos niveles. Las ventanas y los balcones reales se adornaron con telas y tapices y numerosos faroles $y$ hachas iluminaban por la noche este rico aparato. El balcón real disponía de un antepecho, cuyos balaustres de madera imitaban bronces dorados, y de una cristalera. Se trataba, en definitiva, de la construcción efímera de un espacio cuya estructura evoca la de las plazas mayores hispanas en cuanto que lugares escenográficos con arquitecturas pobladas de ventanas para la contemplación del espectáculo. No debe olvidarse tampoco el sentido simbólico de la construcción en cuanto que espacio cívico y políticamente ritualizado ${ }^{42}$.

La plaza efímera del Buen Retiro constituía la abstracción del sentido cívico y político que la plaza tiene para la monarquía absoluta en tanto que lugar apropiado para la celebración y exaltación de sus fiestas y pública expresión de su grandeza. Por otra parte, la estructura regular y uniforme de sus alzados está dentro de la urbanística de los Austrias desde Felipe II y su voluntad política ${ }^{43}$. Pero, además, este espacio constituía un ensayo de lo que a fines de siglo cristalizaria en el modelo hispánico de plaza mayor uniforme y cerrada, cuyo primer ejemplo encontramos en la reforma que se opera en 1687 en la Corredera de Córdoba.

Para asistir a los diferentes festejos que en aquel sitio debian desarrollarse, entre los cuales destacó la espectacular máscara organizada por Olivares con la participación de Cosme Lotti, el rey realizó su entrada

40 Vid. Pizarro Gomez, F. J., op. cit.

${ }^{41}$ «Mandó el Conde allanar junto al Retiro una agradable plaça, en cuya grande, y espaciosa traça se via desde afuera una Troya murada de madera que en el primor, y altura inaccesible fue el crédito imposible su vista milagrosa, tan fuerte, $\tan$ vistosa, que bien pudo ella sola en la apariencia intimarse á si misma competencia, ..." (CARO DE MA. LLEN, A., Contexto de las Reales Fiestas que se hizieron en el Palacio del Buen Retiro a la Coronación de Rey de Romanos, y entrada en Madrid de la Señora Princesa de Cariñán (Madrid 1637), pág. 18.

${ }^{42}$ Vid. Bonet Correa, A., "Concepto de Plaza Mayor en España desde el siglo XVI hasta nuestros días", Morfología y Ciudad. Barcelona 1978, pág. 56.

43 Ibidem, pág. 59 . 
por el acceso a la plaza y que, situado en el frente Norte de la misma, se había elevado a la categoria de arco triunfal.

De esta forma, la ficción de la entrada triunfal en un espacio ideal alcanzó una de sus expresiones más elevadas. La ciudad aquí se simbolizó en uno de sus espacios más característicos como es la plaza mayor, lugar donde como en ningún otro se concentran las posibilidades vitales y los intereses ideológicos de la ciudad, los cuales, como hemos intentado ilustrar, son los auténticos motores de las entradas triunfales españolas de los siglos XVI y XVII. 
